\title{
KINETIC STUDY OF CHARGE TRANSFER COMPLEXES OF IODINE WITH SOME CROWN ETHERS IN NONAQUEOUS SOLVENTS
}

\author{
NINA. ALIZADEH*, AREF. ROOMIANI
}

*Department of Chemistry, University of Guilan, P.B. 1914. Rasht, Iran

(Received: August 26, 2011 - Accepted: March 21, 2012)

\begin{abstract}
Charge-transfer complexation of iodine with 15-crown-5(15C5), dicyclohexyl-18-crown-6 (DC18C6), benzo-18-crown-6 (B18C6) and dibenzo-24-crown-8 (DB24C8) has been studied in chloroform $\left(\mathrm{CHCl}_{3}\right)$, Dichloromethane (DCM) and 1,2-dichloroethane (1,2-DCE) solutions at different time. The results indicated immediate formation of an electron donor-electron acceptor complex; which is followed by two relatively slow consecutive reactions. The pseudo-first-order rate constants for the formation of the ionic intermediate and the final product have been evaluated at $25^{\circ} \mathrm{C}$. The rate of formation of product has been measured as a function of time in different halocarbone solvents. The pseudo first order rate constants were evaluated from the absorbance- time data and found to vary in the order of 1,2-DCE $>\mathrm{DCM}>\mathrm{CHCl}_{3}$.
\end{abstract}

Keywords: Iodine; Charge transfer complex; Spectrophotometry; Kinetic; Crown ether.

\section{INTRODUCTION}

Lariat ethers belong to special class of crown ethers with covalency linked side arm(s), which enhance the binding ability of crown ethers towards metal ions. Many investigations have been carried out on applications of crown ethers in several varieties of areas, such as: chemical analysis [1], in construction of ion-selective electrodes [2,3], solid phase in chromatography column [4]. Studies of crown ethers complexation in different solvents show that the thermodynamic and kinetic parameters and even the mechanism of the complexation processes are affected by the nature and composition of the solvent system [5,6]. Crown ethers are macrocyclic ethers known for their ability to form stable and selective inclusion complexes with many metal ions, including alkali and alkaline earth metal cations [7]. The stability of these complexes appears to be related to the macrocycles cavity sizes; It is at maximum when the cavity diameter matches the ionic size [8]. During the past two decades, a growing interest has been focused on the complexing ability of these macrocyclic ligands as electron-pair molecules towards neutral and, especially, molecular iodine [9-13]. Iodine has been found to form with many compounds charge transfer complexes whose properties have been thoroughly studied [14-18]. Various physico-chemical techniques such as: spectrophotometry [19,20], NMR spectrometry [21], polarography $[22,23]$, potentiometry [24] and conductometry [25-27] have been used to study the complex formation between macrocyclic polyethers (crown ethers) and various metal cations in solutions. Following our previous report on the spectroscopic study of charge transfer complexes of crown ethers with iodine in different halocarbone solvents[9,10], in this paper we report here the results of a spectrophotometric investigation of the kinetics of complex formation of iodine with 15-crown-5 (15C5), dicyclohexyl-18-crown-6 (DC18C6), benzo18-crown-6 (B18C6) and dibenzo-24-crown-8 (DB24C8) in chloroform, dichloromethane and 1,2-dichloroethane solutions.

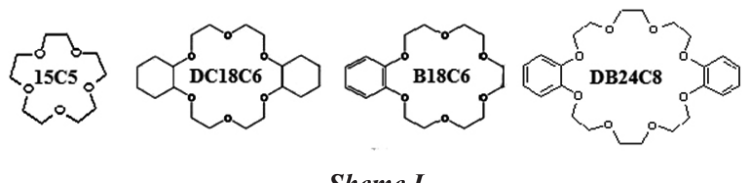

Experimental and apparatus

\section{Reagents}

The macrocycles 15-crown-5 (15C5), Dicyclohexyl-18-crown-6 (DC18C6), Benzo-18-crown-6 (B18C6) and Dibenzo-24-crown-8 (DB24C8) (all from Merck, Sheme I) were of the highest purity available and were used without any further purification. Resublimed iodine of analytical grade (Merck) was used as received. Chloroform, dichloromethane (DCM) and 1,2-dichloroethane (1,2-DCE) (all from Merck) were used as solvents. The characters of these solvent and crown ethers are shown in Table 1. Recording all the electronic spectra and the absorbance measurement at fixed wavelengths were carried out on a model Shimadzu UV-2100 spectrophotometer with $1 \mathrm{~cm}$ quartz cells.

Table 1. The values of polarity and dielectric constant of solvent and values of cavity size of crown ethers.

\begin{tabular}{|c|c|c|c|c|}
\hline Solvent & $\varepsilon / \varepsilon_{0}^{a}$ & $\begin{array}{l}\mu^{\mathrm{b}}(\mathrm{dipole} \\
\text { moment) }\end{array}$ & crown ethers & $\begin{array}{l}\text { Cavity } \\
\text { size }(\AA)^{\mathrm{a}}\end{array}$ \\
\hline Chloroform & 4.81 & 1.04 & $15 \mathrm{C} 5$ & $0.86-0.92$ \\
\hline dichloromethane & 9.08 & 1.55 & $\mathrm{~B} 18 \mathrm{C} 6$ & $1.34-1.55$ \\
\hline \multirow[t]{2}{*}{ 1,2dichloroethane } & 10.3 & 1.8 & DC18C6 & $1.34-1.55$ \\
\hline & & & DB24C8 & $4.5-5.0$ \\
\hline
\end{tabular}

${ }^{\mathrm{a}}$ Reference $[20],{ }^{\mathrm{b}}$ Reference $[21]$

${ }^{2}$ Reference [22]

Procedure

The kinetics of complexes of $\mathrm{I}_{2}$ with 15-crown-5 (15C5), Dicyclohexyl18-crown-6 (DC18C6), Benzo-18-crown-6 (B18C6) and Dibenzo-24-crown-8 (DB24C8) in chloroform 1,2-dichloroethane and dichloromethane was investigated in the different temperatures. In all cases crown to $I_{2}$ mole ratio was $60: 1$. The spectra for each complex at the certain temperature were recorded at different times. The data were obtained for at least $1 \mathrm{~h}$. The stock solution of $I_{2}$ and ligands solutions was freshly made on the day of measurements, but ligands solutions were stable for a long time.

\section{RESULTS AND DISCUSSION}

\section{Absorption spectra studies}

The electronic absorption spectra of mixtures of iodine in the presence of long excess of $15 \mathrm{C} 5, \mathrm{DC} 18 \mathrm{C} 6, \mathrm{~B} 18 \mathrm{C} 6$ and DB24C8 (Crown to $\mathrm{I}_{2}$ mole ratio was 60:1) in chloroform, DCM and 1,2-DCE were obtained as a function of time at $25^{\circ} \mathrm{C}$. Iodine in solution of chloroform, DCM and 1,2-DCE displayed an absorption peak at about $500 \mathrm{~nm}$, while the ligands showed no absorption in the $250-700 \mathrm{~nm}$ region, mixing the solution of ligands to a solution of iodine in each of three solvents resulted in a change of the violet color of the iodine to yellow. It is evident that upon the addition of ligands to the iodine solution the absorption band at $500 \mathrm{~nm}$ which is attributed to the $4 \pi \rightarrow 10 \sigma^{*}$ electronic transition in free iodine [28] is hypsochromically shifted due to its complexation with the added macrocycle. The observed hypsochromic shift in the free iodine band could be attributed to the perturbation of the iodine molecular orbital $10 \sigma^{*}$ by a repulsive interaction between the two components of the charge transfer complex [29-31]. Accordingly, a more repulsive interaction would lead to a large blue shift of the iodine band. Therefore, it is reasonable to consider the extent of the blue shift in iodine band as a measure of the magnitude of interaction between the donor and iodine molecule. The 
limiting value of this shift is at about $355-365 \mathrm{~nm}$, which is the characteristic absorption of the $\mathrm{I}_{3}^{-}$ions in solution [32]. Therefore, it can be concluded that the polarization of the iodine molecule in the complex increases to the extent where a clear-cut separation of charge occurs with the resulting formation of triiodide ion. As seen from Fig.1, one more absorption band appears at about $290 \mathrm{~nm}$. It should be noted that the 292 and $364 \mathrm{~nm}$ are characteristic for the formation of triiodide ion, in the process of complex formation between iodine and different electron pair donor ligands [30-33].

Sample spectra of the absorption spectra of $I_{2}\left(1.0 \times 10^{-3} \mathrm{~mol}^{-\mathrm{L}^{-1}}\right)$ in the presence of large excess of DC18C6 in chloroform solution at $25{ }^{\circ} \mathrm{C}$ was monitored as a function of time in the wavelength range $250-700 \mathrm{~nm}$ are shown in Fig. 1. As Fig.1 shows, while none of the initial reactants show any measurable absorption in $250-450 \mathrm{~nm}$ region, addition of crown ether to the iodine solution results in two strong absorptions bands at this wavelength region, presumably due to the formation of charge-transfer complexes between the crown ethers and iodine which causes the disappearance of a purple color in solution. Obviously, the spectra recorded for the electron donor-acceptor (EDA) complex between ligands and $I_{2}$ are time dependent. The intensities of the different absorptions very fast increase with time, while the general features of the resulting spectra remain unchanged. However, after about $15 \mathrm{~min}$ the purple color of solution begins to disappear slowly and the intensity of the absorption bands in the $250-600 \mathrm{~nm}$ region decrease with time.

This behavior was also observed for complexation of $\mathrm{I}_{2}$ with each four ligands in chloroform solution, but in the case of 1,2-DCE solution, only the decrease of absorption was observed. Figure 2 shows the electronic absorption spectra of DC18C6 with $\mathrm{I}_{2}$ at $25{ }^{\circ} \mathrm{C}$ in the different times in 1,2-DCE solution.

The observed time dependence of the charge-transfer band and the subsequent formation of the $\mathrm{I}_{3}$ - ion in solution are most probably due to a transformation of the initially formed outer complex into an inner EDA complex followed by a fast reaction of the resulting inner complex with iodine to form a triiodide ion, as follows[34,35].

$$
\begin{aligned}
& \mathrm{D}+\mathrm{I}_{2} \rightleftarrows \mathrm{D}-\mathrm{I}_{2} \quad \text { (very fast) (outer complex) } \\
& \mathrm{D}-\mathrm{I}_{2} \longleftrightarrow\left(\mathrm{D}-\mathrm{I}^{+} \mathrm{I}^{-} \quad\right. \text { (slow) (inner complex) } \\
& (\mathrm{D}-\mathrm{I})^{+} \mathrm{I}^{-}+\mathrm{I}_{2} \longleftrightarrow(\mathrm{D}-\mathrm{I})^{+}+\mathrm{I}_{3}^{-} \quad \text { (fast) (final product) }
\end{aligned}
$$

The transformation of the outer CT complex into the corresponding inner complex was found to follow a pseudo-first-order kinetics.

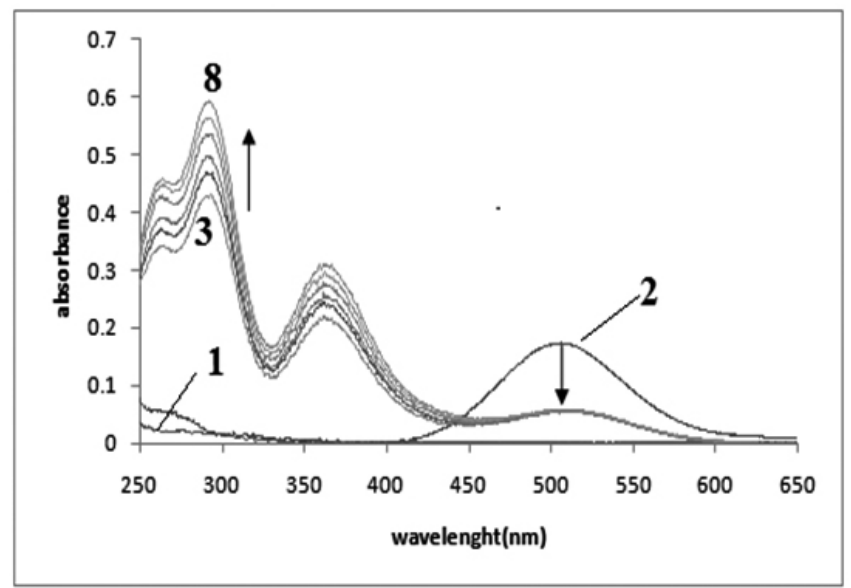

Fig. 1. The UV-Vis spectra of (1) DC18C6 $\left(1 \times 10^{-2} \mathrm{~mol} / \mathrm{L}(2) \mathrm{I}_{2}\left(1 \times 10^{-3}\right.\right.$ $\mathrm{mol} / \mathrm{L}$ ), (3) mixtures of $\mathrm{I}_{2}$ and DC18C6 (ration $60: 1$ ) at $0 \mathrm{~min},(4) 5 \mathrm{~min},(5)$ $15 \mathrm{~min},(6) 25 \mathrm{~min},(7) 60 \mathrm{~min},(8) 120 \mathrm{~min}$ after mixing in chloroform solution at $25^{\circ} \mathrm{C}$.

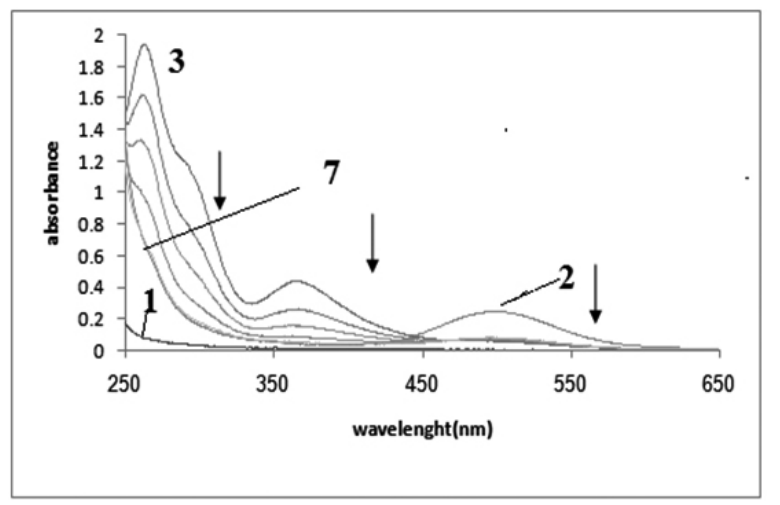

Fig. 2. The UV-Vis spectra of $(1) \mathrm{DC} 18 \mathrm{C} 6\left(1 \times 10^{-2} \mathrm{~mol} / \mathrm{L}\right)(2) \mathrm{I}_{2}\left(1 \times 10^{-3}\right.$ $\mathrm{mol} / \mathrm{L}$ ), (3) mixtures of $\mathrm{I}_{2}$ and DC18C6 (ration 60:1) at $0 \mathrm{~min}$, (4) $5 \mathrm{~min}$, (5) 15 min, (6) $25 \mathrm{~min},(7) 60 \mathrm{~min}$ after mixing in 1,2-DCE solution at $25^{\circ} \mathrm{C}$.

\section{Determination of rate constants}

To obtain the rate constants of charge transfer complexes of $I_{2}$ with ligands, absorbance values of these complexes were recorded at different times. Fig. 3 show the absorbance-time curves DB24C8.I and B18C6.I complexes in chloroform, dichloromethane and 1,2-dichloroethane solution. The above experimental observations seem to be in accord with the following mechanism, which has been proposed before [9-13]. The proposed mechanism for formation of the charge transfer complex as presented at the following:

$$
\mathrm{D}+\mathrm{A} \leftrightarrow \mathrm{DA} \rightarrow \mathrm{D}^{+} \mathrm{A}^{-} \rightarrow \mathrm{P}
$$

Therefore the increase of absorbance in chloroform and dichloromethane arises from $\mathrm{D}^{+} \mathrm{A}^{-}$complex formation and the decrease of absorbance results from $\mathrm{D}^{+} \mathrm{A}^{-}$complex changes to final product. $\mathrm{k}_{1}$ and $\mathrm{k}_{2}$ are the rate constants of first and second steps (i.e. formation of $\mathrm{D}^{+} \mathrm{A}^{-}$complex and resulting product), respectively. In chloroform, dichloromethane solution, the second step is too slow ; only the first step is observed.
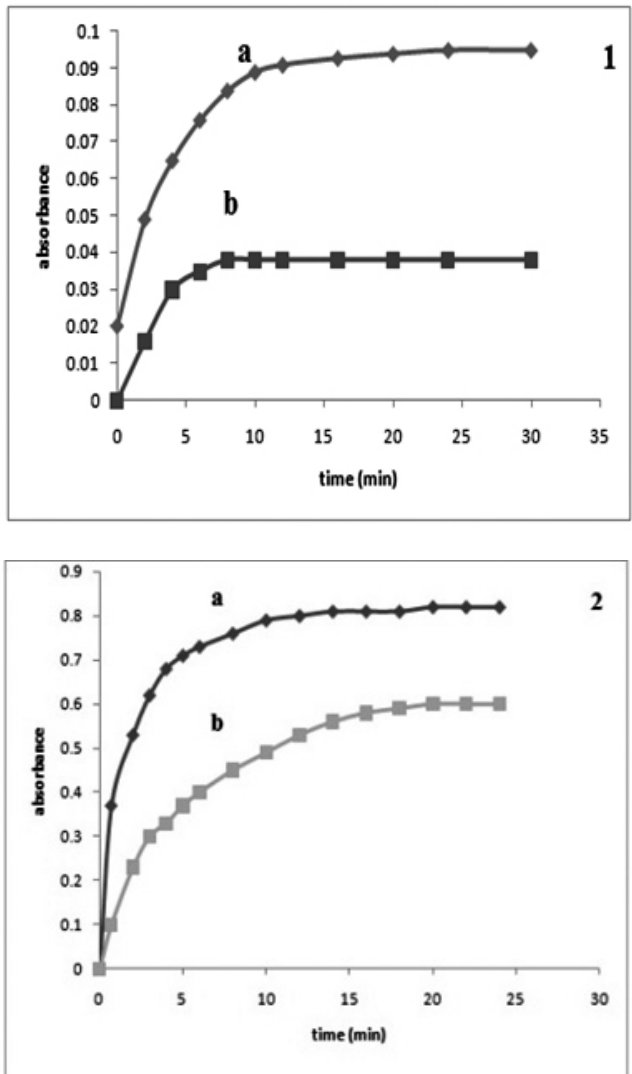


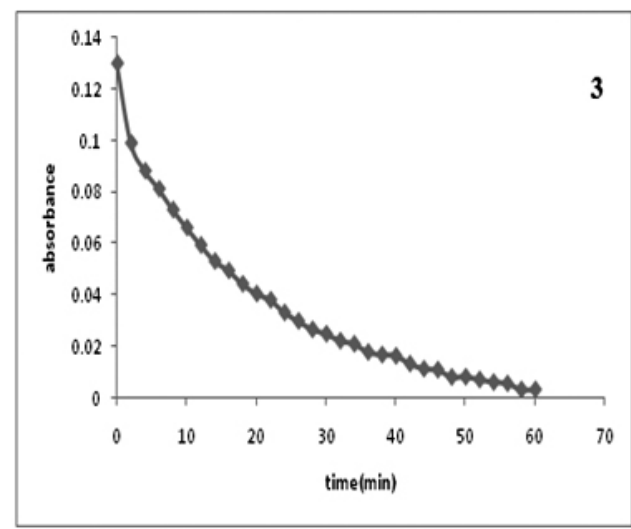

Fig. 3. Absorbance-time curves of (1). (a) DB24C8.I complexes in chloroform solution, (b )dichloromethane solution (2).(a) B18C6.I complexes in chloroform solution, (b )dichloromethane solution (3) B18C6.I complexes in 1,2-dichloroethane solution $25^{\circ} \mathrm{C}$ (concentration of $\mathrm{I}_{2}$ was $1 \times 10^{-3} \mathrm{~mol} \mathrm{~L}^{-1}$ ).

In 1,2-dichloroethane solution, the first step is too fast ; therefore only the second step is observed. In all cases, the absorbance changes were in accord with a pseudo-first-order kinetics. The rate constants were calculated according to a simple first order kinetics model for the reaction between ligands with iodine by the Guggenheim method using the relationshipn:

$$
\ln (\mathrm{A} \infty-\mathrm{At})=-\mathrm{k}\left(\mathrm{t}_{\infty}-\mathrm{t}_{0}\right)+\ln \left(\mathrm{A} \infty-\mathrm{A}_{0}\right)
$$

$\mathrm{A}_{0}, \mathrm{~A}_{\infty}$ and $\mathrm{A}_{t}$ are the measured absorbances at initial, infinite and considered time t, respectively. According to Eq. (2), the $\mathrm{k}$ values can be evaluated from the slope of the resulting $\operatorname{linear} \ln \left(\mathrm{A}_{0}-\mathrm{A}_{\infty}\right)$-time plot.

Table 2. The rate constant values of complexes in chloroform, dichloromethane.

\begin{tabular}{|c|c|c|c|}
\hline ligand & Solvent & $\lambda \max (\mathrm{nm})$ & $10^{2} \mathrm{k}\left(\mathrm{min}^{-1}\right)$ \\
\hline \multirow{2}{*}{$15 \mathrm{C} 5$} & $\mathrm{CHCl}_{3}$ & 385 & 2.1 \\
\hline & DCM & 365 & 3.3 \\
& $1,2-\mathrm{DCE}$ & 365 & 6.1 \\
\hline \multirow{2}{*}{ B18C6 } & $\mathrm{CHCl}_{3}$ & 365 & 4.4 \\
\hline & DCM & 368 & 5.8 \\
\hline \multirow{2}{*}{ DC18C6 } & $1,2-\mathrm{DCE}$ & 370 & 7.8 \\
\hline & $\mathrm{CHCl}_{3}$ & 360 & 7.6 \\
\hline & DCM & 359 & 9.3 \\
& $1,2-\mathrm{DCE}$ & 364 & 15.6 \\
\hline \multirow{2}{*}{ DB24C8 } & $\mathrm{CHCl}$ & 384 & 10.3 \\
& DCM & 388 & 15.9 \\
& $1,2-\mathrm{DCE}$ & 370 & 18.5 \\
\hline
\end{tabular}

The rate constants of $\mathrm{I}_{2}$ complexes in chloroform, dichloromethane and 1,2-dichloroethane are listed in Table 2. As Table 2 shows, the values of the rate constants of complexes are lower than DB24C8-I complex. It is arising of larger cavity of DB24C8 that causes the formation of charge transfer complex to become fast. The increased number of ether donating oxygen atoms available in the ring, as well as their proper spacial positions, are expected to increase the crown-iodine interaction in solution. The values of the rate constants of B18C6- I complex are lower than DC18C6- I complex. The existence of two donating cyclohexyl groups on the $18 \mathrm{C} 6$ ring can pump electrons into the ligand ring and thus increase the basicity of the oxygen atoms. The $15 \mathrm{C} 5-\mathrm{I}_{2}$ system shows the slowest rate in the series, $15 \mathrm{C} 5$ has neither a suitable cavity size for $\mathrm{I}^{+}$ion nor enough flexibility to keep the cation out of the reach of its counter anion. In charge transfer complexes, the values of the rate constants in dichloromethane solution $(\varepsilon=9.1)$ are higher than chloroform solution $(\varepsilon=4.8)$. To be compared with chloroform, dichloromethane has higher polarity and dielectric constant that causes rapid formation of $\mathrm{D}^{+} \mathrm{A}^{-}$complex. Because of the high polarity and dielectric constant of 1,2-dichloroethane (shown in Table 1), the first step (formation of $\mathrm{D}^{+} \mathrm{A}^{-}$complex) in this solution is too fast to be observed. There is actually a considerable decrease in the energy of activation along with an increased dielectric constant of the medium; in a more polar solvent like 1,2-dichloroethane ( $\varepsilon=10.3)$ the transformation (II) proceeds much faster than that in chloroform with $\varepsilon=4.8$. This is in support of the proposed three-step mechanism. In fact, the resulting charged transition states in going from the outer complexes to the inner ones (as the rate determining step of the mechanism) are expected to be more stabilized in 1,2-dichloroethane because of its higher solvating ability and relative permittivity than chloroform. It has been suggested that the observed trend in the stability of the charge-transfer complexes could be due to the high stabilization of the excited states in which the charge is probably more separated than in the ground states.

\section{CONCLUSION}

The kinetic study of formation of these charge transfer complexes shows the role of solvent, the substitute groups on the crown ether ring and the cavity on the crown ether in the reaction rate complex. The formation of the activated complex in the solvent with high polarity and high dielectric constant occurred fast. The electron withdrawing effect of the ligand can cause the rate constant decrease. The rate constants of different crown ether-iodine complexes decreases in the sequence DB24C8> DC18C6> B18C6>15C5.

\section{REFERENCES}

1. H.S. Mehta, V.B. Parikh, U. Pal and S.K. Menon, J. Fluorine Chem., 127, 1228 (2006).

2. L.P. Singh, J.M. Bhatnagar, S. Tanaka, H. Tsu and M. Mori, Anal. Chim. Acta., 546, 199 (2005).

3. M. Jaylakshmi, P. Radhika and M.M. Rao, J. Power Source, 158, 801 (2006).

4. L. Cai, S. Gong, M. Chen and C. Wu, Anal. Chim. Acta, 559, 89 (2006).

5. P. Fux, J. Lagrange and P. Lagrange, J. Am. Chem. Soc., 107, 5927 (1985).

6. B.L. Haymore, J.D. Lamb, R.M. Izatt and J.J. Christensen, J. Inorg. Chem., 21, 1598 (1982).

7. R. M. Izatt, K. Pawlak, J. S. Bradshaw and R. L. Bruening, Chem. Rev., 91, 1721 (1991)

8. S. Kashanian and M. Shamsipur, Inorg. Chim. Acta, 155, 203 (1989).

9. N. Alizadeh and S. Dehghanikhah J. Chin. Chem Letters., Vol. 22, No. 5, pp. 587-590 (2011).

10. N. Alizadeh, M.A. Zanjanchi, H. Sharghi and M. Shamsipur, J. Iran. Chem. Soc(JICS)., Vol. 5, No. 4, pp. 610-616 (2008).

11. A. Semnani and M. Shamsipur, J. Chem. Soc., Dalton Trans., 2215 (1996).

12. L. Andrews, E. S. Prochaska and A. Loewenchuss Inorg. Chem. 19 (1980).

13. M. Shamsipur, F. Mizani, A. A. Saboury, H. Sharghi, R. Khalifeh, Electroanalysis 19, No. 5. 587- 596 (2007).

14. S. Tsurubou, M. Mizatani and Y. Kodota, Anal. Chem., 67, 1465 (1995).

15. M.M. Wienk, T.B. Stowijk and D.N. Reinhoudt, J. Am. Chem. Soc., 112, 797 (1990).

16. L. Cai, S. Gong, M. Chen and C. Wu, Anal. Chim. Acta, 559, 89 (2006)..

17. T.L. Blair, T. Cynkowski and L.G. Bachas, Anal. Chem., 65, 945 (1993).

18. Z. Chen and L. Echegoyen, J. Phys. Org. Chem., 5, 711 (1992).

19. J. Zolghrnein, F. Zahirredini and G. Azimi, Polish. J. Chem., 77, 813 (2003).

20. H.J. Buschmann, E. Cleve, S. Torkler and E. Schollmeyer, Talanta, 51, 145 (2004).

21. A. Nezhadali, G.H. Rounaghi and M. Chamsaz, Bull. Korean Chem. Soc., 21, 685 (2000).

22. M. Chamsaz, G.H. Rounaghi and M.R. Sovizi, Russ. J. Inorg. Chem., 50, 413 (2005).

23. G.H. Rounaghi, A. Sarafrazyazdi and Z. Monsef, J. Incl. Phenom. Macrocycl. Chem., 43, 231 (2002).

24. E. Cukrowska and I. Cukrowski, Talanta, 47, 1175 (1998).

25. G.H. Rounaghi and S. Heydari, Asian J. Chem., 20, 535 (2008).

26. G.H. Rounaghi, M. Rahimi and A. Ghaemi, Asian J. Chem., 20, 299 (2008). 
27. G.H. Rounagi, A. Soleamani and K.R Sanavi, J. Incl. Phenom. Macrocycl. Chem., 58, 43 (2007).

28. R. S. Mulliken, Recl. Trav. Chim. Pays-Bas, 75, 845 (1956).

29. R. S. Mulliken, J. Phys. Chem., 56, 801 (1952).

30. R. S. Mulliken, J. Am. Chem. Soc., 74, 811 (1952).

31. R. S. Mulliken, Recl. Trav. Chim. Pays-Bas, 57, 845 (1956).
32. A. I. Popov and R. F. Swensen, J. Am. Chem. Soc, 77, 3724 (1955).

33. E. M. Nour and L.A. Shahada, Spectrochim. Acta A , 44, 1277 (1988).

34. M. Hasani, M. Shamsipur, Journal of Inclusion Phenomena and Macrocyclic Chemistry.,48, 135 (2004).

35. N.S. Rao, G.B. Rao, D. Ziessov, Spectrochimica Acta., 46A, 1107 (1980). 